\title{
Boundary Layer Slip Flow and Heat Transfer of Nanofluid Induced by a Permeable Stretching Sheet with Convective Boundary Condition
}

\author{
A. Malvandi ${ }^{1 \dagger}$, F. Hedayati ${ }^{2}$ and D. D. Ganji ${ }^{2}$ \\ ${ }^{1}$ Young Researchers and Elite Club, Karaj Branch, Islamic Azad University, Karaj, Iran \\ ${ }^{2}$ Department of Mechanical Engineering, Islamic Azad University, Sari Branch, Sari, Iran \\ †Corresponding Author Email: amirmalvandi@aut.ac.ir
}

(Received February 6, 2014; accepted March 17, 2014)

\begin{abstract}
The objective of this paper is to consider both effects of slip and convective heat boundary conditions on steady twodimensional boundary layer flow of a nanofluid over a stretching sheet in the presence of blowing/suction simultaneously. Flow meets the Navier's slip condition at the surface and Biot number is also used to consider the effects of convective heat transfer. The employed model for nanofluid includes two-component four-equation nonhomogeneous equilibrium model that incorporates the effects of nanoparticle migration owing to Brownian motion and thermophoresis. The basic partial boundary layer equations have been transformed into a two-point boundary value problem via similarity variables. Results for impermeable isothermal surface and also no-slip boundary condition were in best agreements with those existing in literatures. Effects of governing parameters such as Biot number (Bi), slip parameter $(\lambda)$, thermophoresis $(\mathrm{Nt})$, Prandtl number (Pr), Lewis number (Le), Brownian motion $(\mathrm{Nb})$ and blowing/suction $(\mathrm{S})$ on reduced Nusselt and Sherwood numbers are analyzed and discussed in details. The obtained results indicate that unlike heat transfer rate, concentration rate is very sensitive to all parameters among which Le, $\mathrm{S}$ and Pr are the most effective ones.
\end{abstract}

Keywords: Nanofluid, Stretching sheet, Convective boundary condition, Slip flow, Similarity solution.

\section{NOMENCLATURE}

$\begin{array}{llll}a & \text { constant } & p & \text { pressure } \\ \mathrm{C} & \text { nanoparticle volume fraction } & \operatorname{Pr} & \text { Prandtl number } \\ \mathrm{Cf} & \text { skin friction coefficient } & q_{w} & \text { surface heat flux } \\ \mathrm{cp} & \text { specific heat at constant pressure } & \operatorname{Re} & \text { Reynolds number } \\ \mathrm{D}_{\mathrm{B}} & \text { Brownian diffusion coefficient } & S & \text { dimensionless suction/blowing parameter } \\ \mathrm{D}_{\mathrm{T}} & \text { thermophoresis diffusion coefficient } & S h & \text { Sherwood number } \\ \text { Le } & \text { Lewis number } & \gamma \rho & \text { density }\end{array}$

\section{INTRODUCTION}

Improving the technology, limit in enhancing the performance of conventional heat transfer became a main issue owing to low thermal conductivity of the most common fluids such as water, oil, and ethyleneglycol mixture. Since the thermal conductivity of solids is often higher than that of liquids, the idea of adding particles to a conventional fluid to enhance its heat transfer characteristics was emerged. Among all dimensions of particles such as macro, micro and nano, due to some obstacles in the pressure drop

through the system or keeping the mixture homogeneous, nano-scaled particles have attracted more attention. These tiny particles are fairly close in size to the molecules of the base fluid and thus can be realized as extremely stable suspensions with slight gravitational settling over long periods of time. Coined term "nanofluid" was proposed by Choi (1995) to point out engineered colloids composed of nanoparticles dispersed in a base fluid. Following the seminal study of this concept by Masuda et al. (1993), a considerable amount of research in this field has risen exponentially. Meanwhile, theoretical 
studies were emerged to model the nanofluids behaviors. Up to now, the proposed models are twofold; homogeneous flow models and dispersion models. Buongiorno (2006) indicated that the homogeneous models tend to under predict the nanofluid heat transfer coefficient and due to nanoparticle size, dispersion effect is completely negligible. Hence, Buongiorno developed an alternative model to explain the abnormal convective heat transfer enhancement in nanofluids and eliminates the shortcomings of the homogeneous and dispersion models. He considers seven slip mechanisms, including inertia, Brownian diffusion, thermophoresis, diffusiophoresis, Magnus, fluid drainage, gravity and claimed that, of these seven, only Brownian diffusion and thermophoresis are important slip mechanisms in nanofluids. Moreover, Buongiorno concluded that turbulence is not affected by nanoparticles. Based on this finding, he proposed a two-component four-equation non-homogeneous equilibrium model for convective transport in nanofluids. Above-mentioned model has recently been used by Kuznetsov and Nield (2010) to study the influence of nanoparticles on natural convection boundary-layer flow past a vertical plate. Then, a comprehensive survey of convective transport of nanofluids conducted by Khan and Pop (2010), Malvandi et al. (2013), Khan and Aziz (2011), Malvandi (2014), and Malvandi et al. (2014).

Of late, Boundary layer flow of stretching surfaces has attracted considerable attention due to the large number of applications in industry. For instance, many technical processes concerning polymers involve cooling of continuous strips extruded from a die by drawing them through a quiescent fluid with the controlled cooling system, and in this process, the strips are sometimes stretched. Glass blowing, continuous casting of metals, and spinning of fibers also involve the flow over a stretching surface. During the manufacturing process of these sheets, the mixture issued from a slot is stretched to reach the desired thickness. At last, in view of acquiring the top-grade final product, this sheet solidifies as it passes through the air/water-cooled systems. In water cooling systems, inclusion of nanoparticles can enhance the cooling process efficiency and can also reduce the transient time. There is a vast literature on the boundary layer flow over a stretching sheet, but we only refer to few recent studies Ziabakhsh et al. (2010), Hassani et al. (2011), Hayat et al. (2011), Postelnicu and Pop (2011), Malvandi et al. (2013), Malvandi et al. (2013), Reddy (2013). All these investigations employ no-slip condition at the boundary. However, the non-adherence of the fluid to a solid boundary at the presence of nanoparticles, known as slip velocity condition, has been reported by numerous researchers Abbas et al. (2008), Hayat et al. (2008), Hamad et al. (2012), Noghrehabadi et al. (2012), Malvandi et al. (2014), Sharma et al. (2014).

Recently, impacts of the convective boundary condition of nanofluid over a stretching sheet with no slip condition have been studied by Makinde and Aziz (2011). As stated earlier, slip condition occurs in the existence of nanoparticles so the focal point of this paper is to consider both effects of slip flow and convective boundary condition over a stretching sheet. For slip flow, Navier's slip condition is employed and Biot number has been used for describing the convective boundary condition. Serving as a complement to the previous studies, effects of suction/injection, Lewis and Prandtl numbers on heat and concentration rates have been considered in a wide variety of Brownian motion and thermophoresis parameters.

\section{MATHEMATICAL Formulation}

Consider the steady, two-dimensional incompressible slip flow of nanofluids past a permeable stretching sheet in the presence of blowing/suction as shown in fig. 1. The sheet is stretched with a velocity $u_{w}(x)=a x$ where $a$ is constant. It is worth mentioning that the surface temperature $T_{w}$ is a result of the convective heat process which characterized by a temperature $T_{f}$ and $a$ heat transfer coefficient $h$. The nanoparticle volume fraction at the wall is $\mathrm{C}_{\mathrm{w}}$, while the ambient temperature and concentration at large values of $y$ having constant values $\mathrm{T}_{\infty}$ and $\mathrm{C}_{\infty}$ respectively. The basic unsteady incompressible conservation equations of mass, momentum, the thermal energy of nanofluid can be expressed as Kuznetsov and Nield (2010).

$\frac{\partial u}{\partial x}+\frac{\partial v}{\partial y}=0$

$u \frac{\partial u}{\partial x}+v \frac{\partial u}{\partial y}=v\left(\frac{\partial^{2} u}{\partial x^{2}}+\frac{\partial^{2} u}{\partial y^{2}}\right)-\frac{1}{\rho} \frac{\partial p}{\partial x}$

$u \frac{\partial T}{\partial x}+v \frac{\partial T}{\partial y}=\alpha\left(\frac{\partial^{2} T}{\partial x^{2}}+\frac{\partial^{2} T}{\partial y^{2}}\right)$

$+\tau\left[\begin{array}{l}D_{B}\left(\frac{\partial C}{\partial x} \frac{\partial T}{\partial x}+\frac{\partial C}{\partial y} \frac{\partial T}{\partial y}\right) \\ +\frac{D_{T}}{T_{\infty}}\left(\frac{\partial T^{2}}{\partial x}+\frac{\partial T^{2}}{\partial y}\right)\end{array}\right]$

$u \frac{\partial C}{\partial x}+v \frac{\partial C}{\partial y}=D_{B}\left(\frac{\partial^{2} C}{\partial x^{2}}+\frac{\partial^{2} C}{\partial y^{2}}\right)$

$$
+\frac{D_{T}}{T_{\infty}}\left(\frac{\partial^{2} T}{\partial x^{2}}+\frac{\partial^{2} T}{\partial y^{2}}\right)
$$

subject to the boundary conditions

$$
\begin{aligned}
& \left(\begin{array}{c}
u=u_{w}+N v \frac{\partial u}{\partial y}, v=v_{w}, \\
h\left(T_{f}-T\right)=-k \frac{\partial T}{\partial y}, C=C_{w}
\end{array}\right. \\
& u=0, \quad T=T_{\infty}, \quad C=C_{\infty} \text { As } y \rightarrow \infty
\end{aligned}
$$

where $\mathrm{u}$ and $\mathrm{v}$ are the velocity components along the $x$ and $y$ coordinates, $N$ is the velocity slip factor, $\rho$ is the density of the base fluid, $p$ is the pressure, $\alpha$ is the thermal diffusivity, $v$ is the kinematic viscosity, $\mathrm{k}$ is the thermal conductivity, $D_{B}$ is the Brownian diffusion 


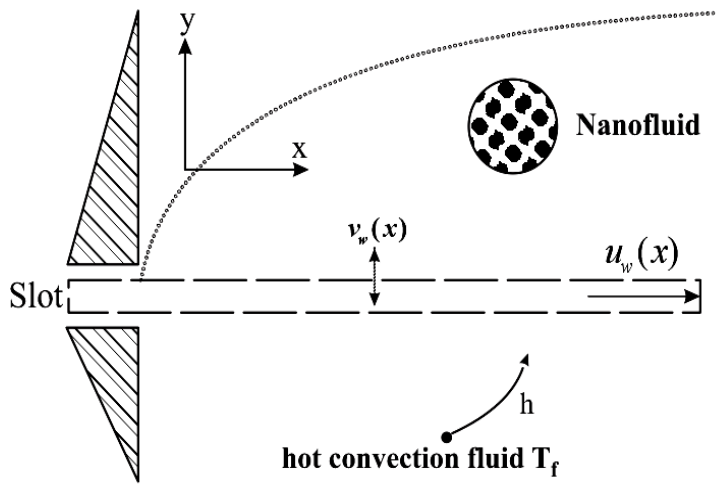

Fig. 1. The geometry of physical model and coordinate system

coefficient, $D_{T}$ is the thermophoretic diffusion coefficient, is the ratio between the effective heat capacity of the nanoparticle material and heat capacity of the fluid, $c p, T$ are specific heat at constant temperature and local temperature respectively. Employing the following similarity parameters

$$
\begin{aligned}
& \psi=a x(v)^{1 / 2} f(\eta), \quad \eta=(v)^{-1 / 2} y, \\
& \theta(\eta)=\frac{T-T_{\infty}}{T_{f}-T_{\infty}}, \quad \phi(\eta)=\frac{C-C_{\infty}}{C_{w}-C_{\infty}}
\end{aligned}
$$

Eqs. (1)-(4) collapse into

$$
\begin{aligned}
& f^{\prime \prime \prime}+f^{\prime \prime} f+f^{\prime}\left(1-f^{\prime}\right)=0 \\
& \theta^{\prime \prime}+\operatorname{Pr} \theta^{\prime}\left(N b \phi^{\prime}+N t \theta^{\prime}\right)+\operatorname{Pr} \theta=0 \\
& \phi^{\prime \prime}+\operatorname{Le\phi } f+\frac{N t}{N b} \theta^{\prime \prime}=0
\end{aligned}
$$

And the transformed boundary condition of Eq. (5) reduces to

$$
\begin{aligned}
& \eta=0:\left(\begin{array}{c}
f=S, \quad f^{\prime}=1+\lambda f^{\prime \prime}, \\
\theta^{\prime}=-B i(1-\theta), \quad \phi=1
\end{array}\right. \\
& \eta \rightarrow \infty: f^{\prime}=0, \quad \theta=0, \quad \phi=0
\end{aligned}
$$

where ' denotes differentiation with respect to $\eta$ and the outcoming non-dimensional parameters are

$$
\begin{aligned}
& P r=\frac{v}{\alpha}, \quad L e=\frac{v}{D_{B}}, A^{*}=\frac{Q_{0}}{\left(\rho c_{p}\right)_{p} t}, \\
& B i=\frac{h \sqrt{v t}}{k}, N t=\frac{\left(\rho c_{p}\right)_{p} D_{T}\left(T_{f}-T_{\infty}\right)}{\left(\rho c_{p}\right)_{f} v T_{\infty}}, \\
& N b=\frac{\left(\rho c_{p}\right)_{p} D_{B}\left(C_{w}-C_{\infty}\right)}{\left(\rho c_{p}\right)_{f} v}, \lambda=N \sqrt{v}
\end{aligned}
$$

Here $\mathrm{Pr}, \mathrm{Le}, \mathrm{Nb}, \mathrm{Nt}$, and $\lambda$ denote the Prandtl number, the Lewis number, the Brownian motion, the thermophoresis and slip parameter, respectively. The skin friction coefficient, the local Nusselt and Sherwood numbers can be defined as:

$$
\begin{aligned}
C_{f} & =\frac{\tau_{w}}{\rho u_{\infty}{ }^{2}}, \quad N u=\frac{x q_{w}}{K\left(T_{w}-T_{\infty}\right)}, \\
S h & =\frac{x q_{m}}{D_{B}\left(C_{w}-C_{\infty}\right)}
\end{aligned}
$$

where $\tau_{\mathrm{w}}$ is the surface shear stress and, $\mathrm{q}_{\mathrm{w}}$ and $\mathrm{q}_{\mathrm{m}}$ are heat and mass flux at the surface respectively which are defined as follows

$$
\begin{aligned}
& \tau_{w}=\mu\left(\frac{\partial u}{\partial y}\right)_{y=0}, q_{w}=-k\left(\frac{\partial T}{\partial y}\right)_{y=0}, \\
& q_{m}=-D_{B}\left(\frac{\partial C}{\partial y}\right)_{y=0}
\end{aligned}
$$

using the dimensionless variables Eq. (6), the rate of skin friction, heat transfer and concentration can be written as

$$
\begin{aligned}
& C f r=R e_{x}{ }^{-1 / 2} C_{f}=f^{\prime \prime}(0), \\
& \text { Nur }=R e_{x}^{-1 / 2} N u=-\theta^{\prime}(0), \\
& \text { Shr }=R e_{x}{ }^{-1 / 2} S h=-\phi^{\prime}(0)
\end{aligned}
$$

Here Cfr, Nur, Shr refers to reduced skin friction coefficient, the reduced Nusselt number and reduced Sherwood number respectively. Also, $R e_{x}=u_{w} x / v$ is the local Reynolds number base sheet's velocity.

\section{RESUlts and Discussions}

The system of Eqs. (7)-(9) with boundary conditions of Eq. (10) have been solved numerically via RungeKutta-Fehlberg method. The best accuracy of results is obtained for the case of the isothermal impermeable case with Noghrehabadi et al. (2012) and also for the case of no-slip impermeable boundary condition with Makinde and Aziz (2011) which are cited in Table 1 and Table 2, respectively. In comparison with regular fluids, the present extension involves three more parameters: $\mathrm{Nt}, \mathrm{Nb}$ and Le. Hence, contour plots have been presented instead of regular diagrams. The advantage of contour lines is that they illustrates more physical interpretation rather than common plots and suits for complicated problems that depend on various parameters. Here, in all contours, the negative values have been shown with dashed lines. For a typical nanofluid, $\mathrm{Nb}$ and $\mathrm{Nt}$ varies between 0 to 1 and $\mathrm{Le}$ varies up to 20, see Makinde and Aziz (2011). It should also be stated at the outset that one error is inevitable, because the physical domain is unbounded where as the computational domain has to be finite. Here, for our bulk computations, the far field boundary conditions denoted by $\eta_{\max }$ set to $\eta_{\max }=15$ which was sufficient enough to achieve the far field boundary conditions asymptotically. 
Table 1 Comparison of our results for reduced Nusselt and Sherwood numbers when $\mathrm{Le}=\operatorname{Pr}=10, \lambda=1, \mathrm{Bi}=\infty, \mathrm{S}=\mathbf{0}$.

\begin{tabular}{ccccccc}
\hline \multirow{2}{*}{$\mathrm{Nb}$} & $\mathrm{Nt}$ & \multicolumn{2}{c}{ Nur } & & \multicolumn{2}{c}{ Shr } \\
\cline { 3 - 4 } \cline { 6 - 6 } \cline { 6 - 6 } & & Noghrehabadi et al. (2012) & Present result & & Noghrehabadi et al. (2012) & Present result \\
\hline \multirow{2}{*}{0.1} & 0 & 0.718928 & 0.719 & & 1.60743 & 1.607 \\
& 0 & 0.392596 & 0.393 & & 1.908809 & 1.909 \\
& 1 & 0.242357 & 0.242 & & 2.291156 & 2.291 \\
& 1 & - & 0.167 & & - & 2.57 \\
0.3 & 0 & 0.190347 & 0.19 & & 1.819268 & 1.819 \\
& 0 & 0.102297 & 0.102 & & 1.969337 & 1.969 \\
& 1 & 0.06288 & 0.063 & & 2.077327 & 2.077 \\
& 1 & - & 0.043 & & - & 2.148 \\
\hline
\end{tabular}

Table 2 Comparison of our results for reduced Nusselt and Sherwood numbers when $\mathrm{Le}=5, \mathrm{~S}=\lambda=0, \mathrm{Nt}=\mathrm{Nb}=0.5$

\begin{tabular}{ccccccc}
\hline \multirow{2}{*}{$\operatorname{Pr}$} & Bi & \multicolumn{2}{c}{ Nur } & & \multicolumn{2}{c}{ Shr } \\
\cline { 3 - 4 } \cline { 6 - 6 } \cline { 6 - 6 } & & Makinde and Aziz (2011) & Present result & & Makinde and Aziz (2011) & Present result \\
\hline 1 & 0.1 & 0.0789 & 0.0789 & & 1.5477 & 1.5477 \\
5 & 0.1 & 0.0735 & 0.0735 & & 1.5983 & 1.5983 \\
10 & 0.1 & 0.0387 & 0.0387 & & 1.7293 & 1.7293 \\
5 & 1 & 0.1476 & 0.1476 & & 1.6914 & 1.6914 \\
5 & 10 & 0.155 & 0.155 & & 1.7122 & 1.7122 \\
5 & 100 & 0.1557 & 0.1557 & & 1.7144 & 1.7144 \\
\hline
\end{tabular}

Brownian motion can be observed due to random drifting of suspended nanoparticles; on the other hand, thermophoresis involves nanoparticle migration due to the imposed temperature gradient across the fluid. In fact, the Brownian motion and thermophoretic forces go up against and also affect each other. Therefore, the results should be carried out for a wide range of Brownian motion and thermophoretic parameters to reveal their effects. For doing so, the contour lines of $N b-N t$ have been shown in Figs. 2-6 to illustrate the effects of Brownian motion (Nb), thermophoresis $(\mathrm{Nt})$, Lewis number (Le), slip parameter $(\lambda)$, blowing/suction (S) and Prandtl number (Pr) on reduced Nusselt and Sherwood numbers. As it is obvious, heat transfer rate (Nur) varies almost linearly with all parameters. Accordingly, an increase in the values of $\mathrm{Nt}, \mathrm{Nb}$, Le and $\lambda$ decreases Nur while an increase in the value of $\mathrm{Bi}, \operatorname{Pr}$ and suction parameter increase Nur. Fig. 2 reveals that the value of reduced Nusslet number is higher for the case of suction $S>0$ comparing with the blowing case $S<0$; this is a result from the fact that once the fluid is drawn across the blowing wall, both the hydrodynamic and thermal boundary layers become thicker. Thicker thermal boundary layers lead to some decreases in the temperature gradients on the sheet, which reduces the heat transfer rate. A reverse situation takes place in the boundary layer with suction. The Lewis number is an effective parameter which defines the ratio of the thermal diffusivity to the mass diffusivity. Its effect on the heat transfer rate is shown in Fig. 3. Le is applied to characterize the fluid flows where simultaneous heat and mass transfer occur because of the convection. Obviously, an increase in the values of Lewis number leads to a drop in the values of the reduced Nusselt number.

From Fig. 5, it can be concluded that a convective heat transfer at the surface decreases the reduced Nusselt number. Not surprisingly, increasing the value of the Biot number diminishes the total thermal resistance of the system. Moreover, the effects on the heat transfer rate are observed to be more pronounced for the higher values of the Biot number compared with the lower ones. It is worth mentioning that in all of these parameters, suction and Prandtl number have the greatest impacts on heat transfer rates.

In spite of reduced Nusselt number, we can observe that reduced Sherwood number is very sensitive to all parameters and its variations are not predictable at a glance. The right column of Fig. 2 shows how concentration rates vary with $\mathrm{S}$. Considering the figure we can realize that for $\mathrm{Nb}>0.1$, as $\mathrm{S}$ grows from its negative values (blowing) to its positive ones (suction), concentration rate takes an increasing trend. In other words, for the case of suction, the values of concentration rate are greater than that of impermeable wall; a similar behavior can be seen between the 


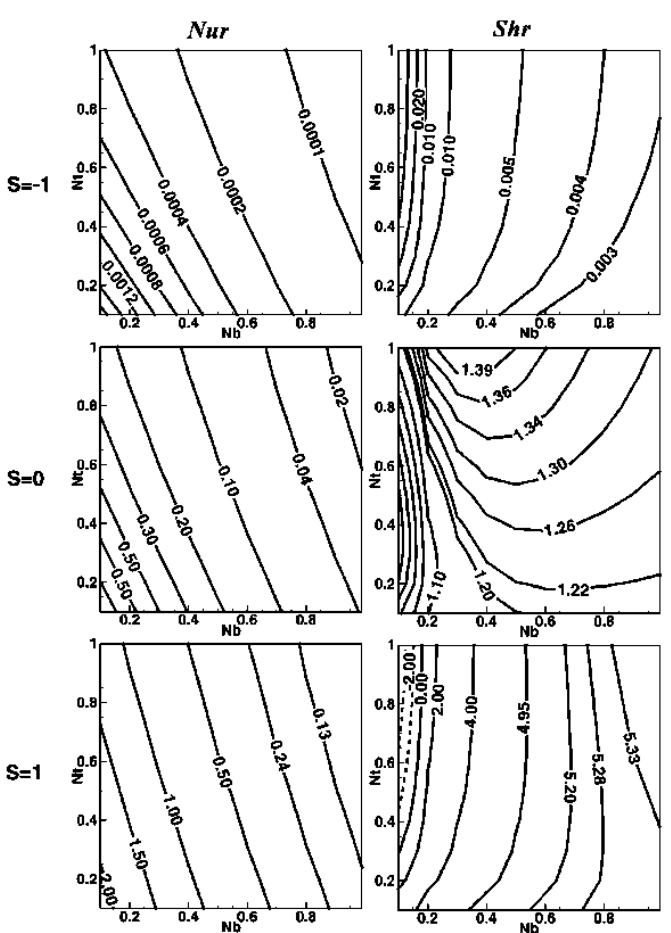

Fig. 2. Contour lines of reduced Nusselt and Sherwood numbers for different values of blowing/suction parameter $S$ when Le $=B i=\operatorname{Pr}=5, \lambda=1$
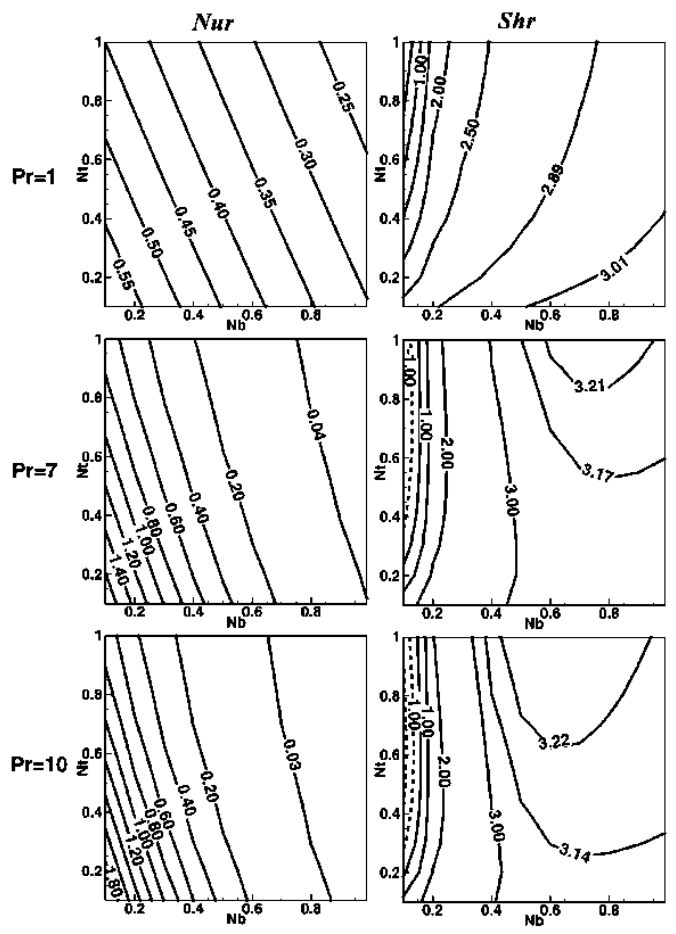

Fig. 4. Contour lines of reduced Nusselt and Sherwood numbers for different values of Prandt number $\operatorname{Pr}$ when $S=0.5, L e=B i=5, \lambda=1$



Fig. 3. Contour lines of reduced Nusselt and Sherwood numbers for different values of Lewis number $L e$ when $S=0.5, B i=\operatorname{Pr}=5, \lambda=1$
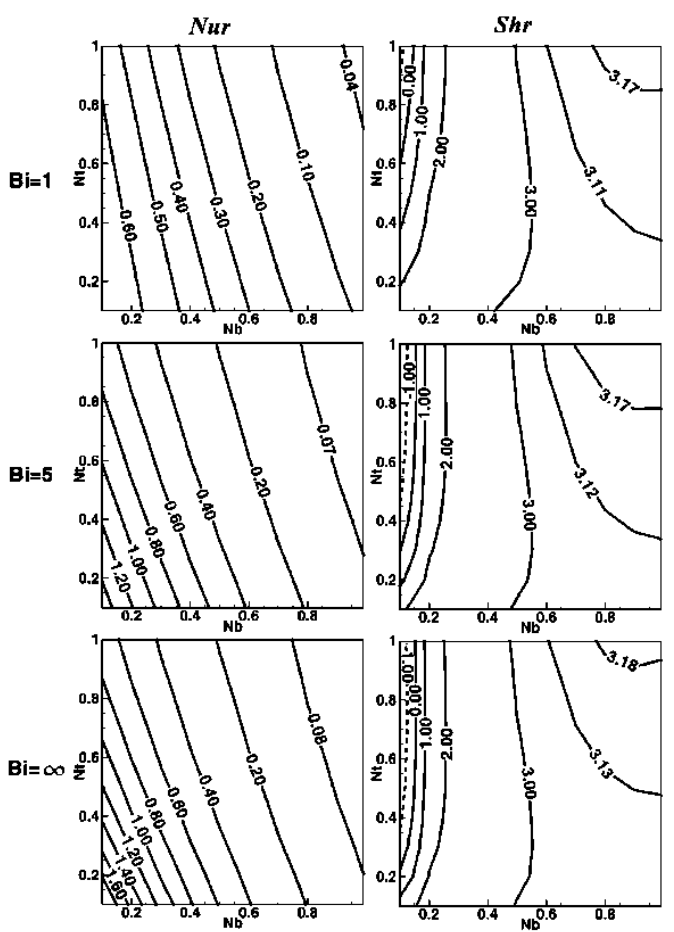

Fig. 5. Contour lines of reduced Nusselt and Sherwood numbers for different values of Biot number $B i$ when $S=0.5, L e=\operatorname{Pr}=5, \lambda=1$ 


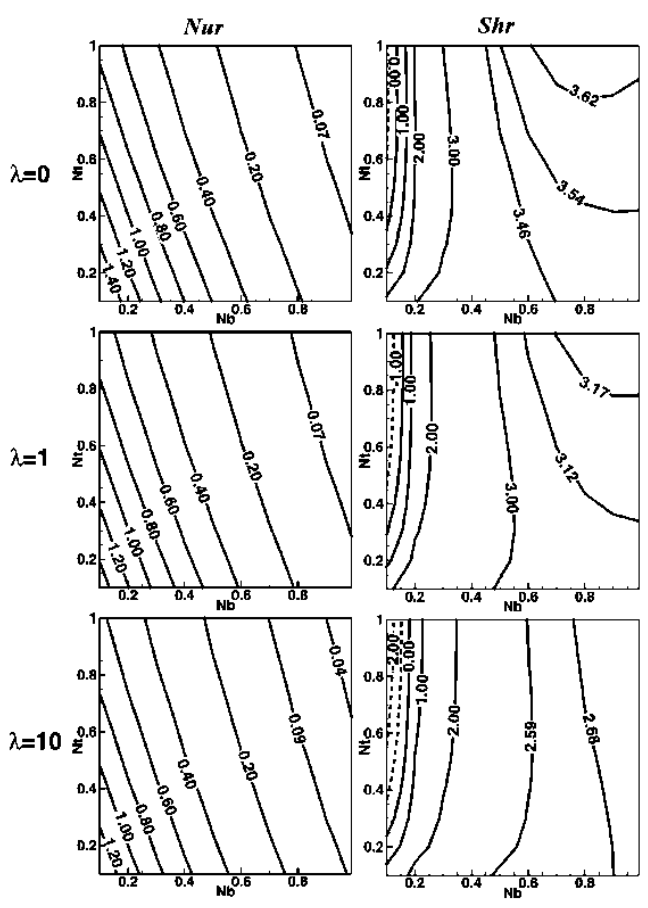

Fig. 6. Contour lines of reduced Nusselt and Sherwood numbers for different values of dimensionless slip factors $\lambda$ when $S=0.5, L e=B i=P r=5$

impermeable wall and blowing cases. However, increasing in the values of $\mathrm{S}$ For $\mathrm{Nb}<0.1$ drops $\mathrm{Shr}$ which is negative (reversed the concentration rate) for the high suction case. This phenomenon vanishes when Lewis number increases (Fig. 3) or any of the suction parameter (Fig. 2), Prandtl number (Fig. 4), Biot number (Fig. 5) and slip velocity (Fig. 6) decreases.

Also, as the eye sees, blowing/suction parameter has marked effects on Shr's contour lines' pattern. For the strong blowing case, i.e. $S=-1$, increasing in the values of $\mathrm{Nb}$ leads to a drop in the value of Shr, however, in the case of suction this trend is vice versa. Referring to Fig. 3, it is observable that for lower values of Le as $\mathrm{Nb}$ grows $\mathrm{Shr}$ increases while rising in the values of Le can change this trend particularly for the high Brownian motion parameter. What is more, in the region of lower Brownian motion numbers, increasing in the values of Lewis number cause a marked decrease in the values of concentration rate; according to Fig. 4, the same trend for Prandtl number is governed. Regarding Fig. 5, we can observe that Biot number has negligible effects on the reduced Sherwood number where an increase in the values of the Biot number from unity to infinity, results a gentle rise (less than $0.3 \%$ ) in the reduced Sherwood number; in contrast to Biot number, slip parameter has significant effects where a rise in the values of slip parameter lead to decrease in the value of reduced Sherwood number, see Fig. 6.

The samples of velocity, temperature and concentration profiles for selective values of parameters are presented in Fig. 7, Fig. 8 and Fig 9. These profiles have essentially the same form as the case of regular fluids.

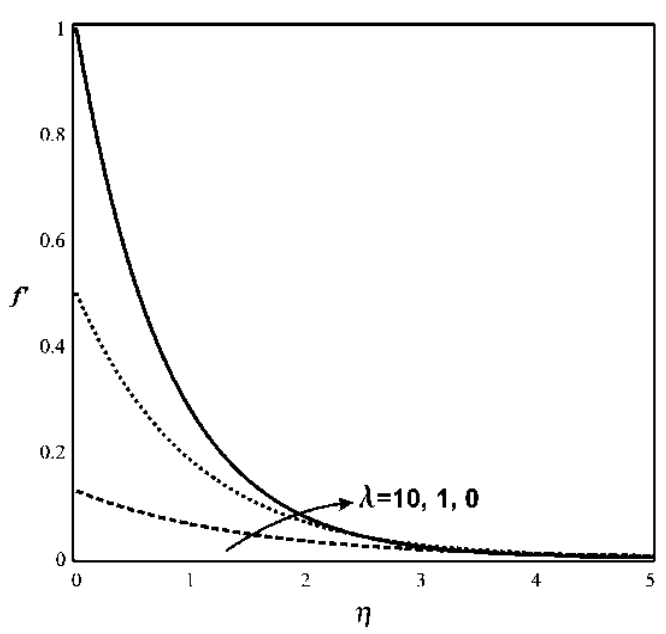

Fig. 7. Effects of dimensionless slip factor on velocity profile when

$N b=N t=0.1, B i=P r=L e=5, S=0.5$

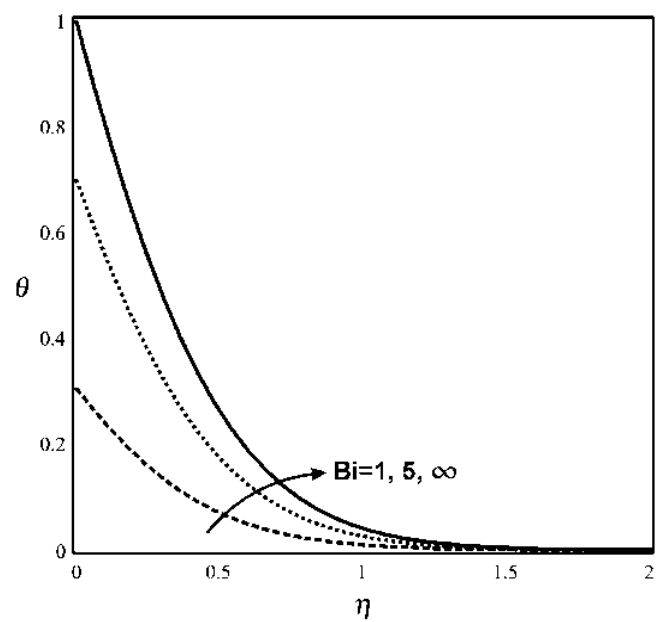

Fig. 8. Effects of Biot number on temperature profile when

$N b=N t=0.1, P r=L e=5, \lambda=1, S=0.5$

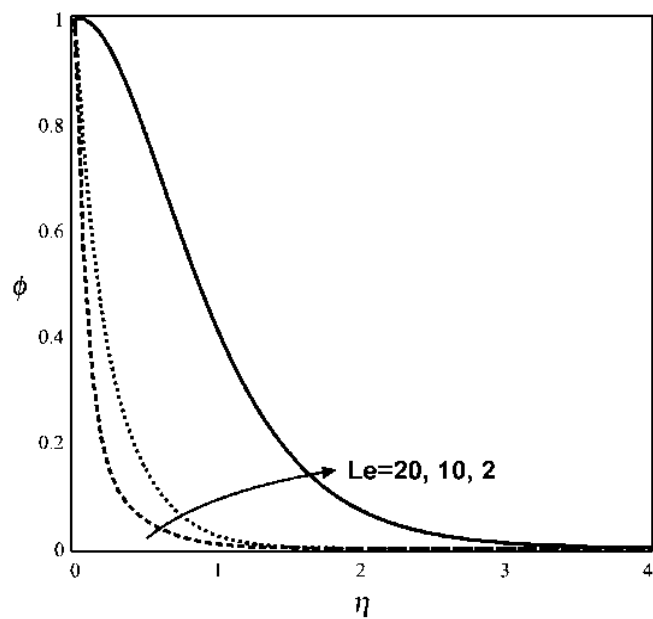

Fig. 9. Effects of Lewis number on concentration profile when

$N b=N t=0.1, B i=\operatorname{Pr}=5, \lambda=1, S=0.5$ 
The figures show solutions satisfy far field boundary conditions and can be used for validity of our results as well as illustrating how Lewis, Biot and slip velocity parameters influence the boundary layers and provide a physical insight into the mentioned explanations. Considering Fig. 7, It can be realized that a rise in the values of slip parameter generates more momentum inside the boundary layer which is the reason for the reduction in heat and concentration rates. Fig. 8 displays that the surface temperature increases as the Biot number climbs up, as a result, heat transfer rate experiences a rise. Finally, Fig. 9 demonstrates that decreasing in the values of Lewis number enhances the concentration profiles until the variational trend on the sheet changes which causes reversed the concentration rate (see Fig. 3).

\section{Summary and Conclusion}

Boundary layer slip flow and heat transfer of nanofluid over a permeable stretching sheet with the convective boundary condition has been investigated numerically. Despite of the conventional no-slip boundary conditions, in the present study, the partial slip boundary condition has been applied. Two-component four-equation nonhomogeneous equilibrium model that incorporates the effects of nanoparticle migration owing to the Brownian motion and thermophoresis has been employed to consider the effects of nanofluid (mixture

\section{REFERENCES}

Abbas, Z., T. Hayat, M. Sajid, S. Asghar (2008), Unsteady flow of a second grade fluid film over an unsteady stretching sheet. Mathematical and Computer Modelling 48, 3-4, 518-526

Buongiorno, J. (2006), Convective Transport in Nanofluids. Journal of Heat Transfer 128, 3, 240250

Choi, S. U. S. (1995), Enhancing thermal conductivity of fluids with nanoparticles. in Developments and Applications of Non-Newtonian Flows, D. A. Siginer and H. P. Wang, Eds., ASME 66, 99-105

Hamad, M. A. A., M. J. Uddin, A. I. M. Ismail (2012), Investigation of combined heat and mass transfer by Lie group analysis with variable diffusivity taking into account hydrodynamic slip and thermal convective boundary conditions. International Journal of Heat and Mass Transfer 55, 4, 13551362

Hassani, M., M. Mohammad Tabar, H. Nemati, G. Domairry, F. Noori (2011), An analytical solution for boundary layer flow of a nanofluid past a stretching sheet. International Journal of Thermal Sciences 50, 11, 2256-2263

Hayat, T., T. Javed , Z. Abbas (2008), Slip flow and heat transfer of a second grade fluid past a stretching sheet through a porous space. International Journal of Heat and Mass Transfer $51,17-18,4528-4534$ of water with particles $<100 \mathrm{~nm}$ ). The bold outcomes of this study can be summarized as follows:

- Increasing in the values of $\mathrm{Nt}, \mathrm{Nb}, \mathrm{Le}$ and $\lambda$ lead to decrease heat transfer rate Nur while increasing in the value of $\mathrm{Bi}, \mathrm{Pr}$ and $\mathrm{S}$ increase Nur.

- For lower values of $\mathrm{Le}$, as $\mathrm{Nb}$ grows (nanoparticles gets smaller), Shr increases while rising in the values of Le can change this trend particularly for higher values of Brownian motion parameters. What is more, in the region of lower Brownian motion numbers, increasing in the values of Lewis number cause a marked decrease in the values of concentration rate.

- For lower values of $\mathrm{Nb}$ (larger nanoparticles), in the case of high suction, Shr is negative, i.e. reversed the concentration rate occurs which vanishes when Lewis number increases or any of the suction parameter, Prandtl number, Biot number and slip velocity decreases.

- Biot number has negligible effects on reduced Sherwood number where increase in the values of Biot number from unity to infinity, results a gentle rise (less than $0.3 \%$ ) in the reduced Sherwood number; in contrast to Biot number, slip parameter has significant effects where a rise in the values of slip parameter lead to decrease in the value of the reduced Sherwood number.

Hayat, T., M. Nawaz, S. Obaidat (2011), Axisymmetric magnetohydrodynamic flow of micropolar fluid between unsteady stretching surfaces. Applied Mathematics and Mechanics 32, 3, 361-374

Khan, W. A. , A. Aziz (2011), Natural convection flow of a nanofluid over a vertical plate with uniform surface heat flux. International Journal of Thermal Sciences 50, 7, 1207-1214

Khan, W. A. , I. Pop (2010), Boundary-layer flow of a nanofluid past a stretching sheet. International Journal of Heat and Mass Transfer 53, 11-12, 2477-2483

Kuznetsov, A. V., D. A. Nield (2010), Natural convective boundary-layer flow of a nanofluid past a vertical plate. International Journal of Thermal Sciences 49, 2, 243-247

Makinde, O. D., A. Aziz (2011), Boundary layer flow of a nanofluid past a stretching sheet with a convective boundary condition. International Journal of Thermal Sciences 50, 7, 1326-1332

Malvandi, A., The Unsteady Flow of a Nanofluid in the Stagnation Point Region of a Time-dependent Rotating Sphere. Thermal Science

Malvandi, A., D. D. Ganji, F. Hedayati, E. Yousefi Rad (2013), An analytical study on entropy generation of nanofluids over a flat plate. Alexandria Engineering Journal 52, 4, 595-604 
Malvandi, A., F. Hedayati , G. Domairry (2013), Stagnation point flow of a nanofluid toward an exponentially stretching sheet with nonuniform heat generation/absorption. Journal of Thermodynamics

Malvandi, A., F. Hedayati, D. D. Ganji (2014), Slip effects on unsteady stagnation point flow of a nanofluid over a stretching sheet. Powder Technology 253, 0, 377-384

Malvandi, A., F. Hedayati, M. R. H. Nobari (2014), An HAM Analysis of Stagnation-Point Flow of a Nanofluid over a Porous Stretching Sheet with Heat Generation. Journal of Applied Fluid Mechanics 7, 1, 135-145

Malvandi, A., F. Hedayeti, D. Ganji, Y. Rostamiyan (2013), Unsteady boundary-layer flow of nanofluid past a permeable stretching/shrinking sheet with convective heat transfer. Proceedings of the Institution of Mechanical Engineers, Part C: Journal of Mechanical Engineering Science

Malvandi, A., S. A. Moshizi, E. G. Soltani, D. D. Ganji (2014), Modified Buongiorno's model for fully developed mixed convection flow of nanofluids in a vertical annular pipe. Computers \& Fluids 89, 0, 124-132

Masuda, H., A. Ebata, K. Tirana, N. Hishinuma (1993), Alteration of thermalconductivity and viscosity of liquid by dispersing ultra-fine particles. Netsu Bussei 7, 4

Noghrehabadi, A., R. Pourrajab, M. Ghalambaz (2012), Effect of partial slip boundary condition on the flow and heat transfer of nanofluids past stretching sheet prescribed constant wall temperature. International Journal of Thermal Sciences 54, 0, 253-261

Postelnicu, A., I. Pop (2011), Falkner-Skan boundary layer flow of a power-law fluid past a stretching wedge. Applied Mathematics and Computation 217, 9, 4359-4368
Reddy, M. G. (2013), Lie Group Analysis of Heat and Mass Transfer Effects on Steady MHD Free Convection Flow past an Inclined Surface with Viscous Dissipation. Journal of Applied Fluid Mechanics 6, 3, 397-404

Sharma, R., A. Ishak, R. Nazar, I. Pop (2014), Boundary Layer Flow and Heat Transfer over a Permeable Exponentially Shrinking Sheet in the Presence of Thermal Radiation and Partial Slip. Journal of Applied Fluid Mechanics 7, 1, 125-134

Ziabakhsh, Z., G. Domairry, M. Mozaffari , M. Mahbobifar (2010), Analytical solution of heat transfer over an unsteady stretching permeable surface with prescribed wall temperature. Journal of the Taiwan Institute of Chemical Engineers 41, $2,169-177$

Anson, M. and 1. Zhang (1995, July). On-site graphics for planning and communicating the use of site space. In Y. Loo (Ed.), Proceedings of the Fifth East Asia-Pacific Conference on Structural Engineering and Construction, Gold Coast, Australia, pp. 883-888. Griffith University.

Ho, W. (1991). Nonlinear Analysis of Steel Frames with Semi-Rigid Connections. Ph. D. thesis, the Hong Kong Polytechnic University, Hong Kong, China.

Ko, 1., Y. Ni, and Q. Tian (1992). Hysteretic behavior and empirical modelling of a wirecable vibration isolator. International Journal of Analytical and Experimental Modal Analysis 7(2),111-127.

Ko, 1. and Y. Xu (2000, December). Title of paper. In Proceedings of International Conference on Advances in Structural Dynamics, Hong Kong, China.

Teng, 1., 1. Chen, S. Smith, and L. Lam (2002). FRPStrengthened RC Structures. Chichester, UK.: John Wiley and Sons. 